\title{
PRÁTICAS \\ MULTILETRADAS \\ POTENCIALIZADAS \\ COM USO DAS TECNOLOGIAS \\ DIGITAIS NO CONTEXTO \\ DO PROFLETRAS \\ / REGIÃO CENTRO-OESTE ${ }^{1}$
}

\section{PRÁCTICAS DE ALFABETIZACIÓN MÚLTIPLE POTENCIALIZADAS CON EL USO DE LAS TECNOLOGÍAS DIGITALES EN EL CONTEXTO DEL PROFLETRAS/REGIÓN CENTRO OESTE}

POTENTIALIZED MULTILITERACY PRACTICES WITH THE USE OF DIGITAL TECHNOLOGIES IN THE PROFLETRAS/MIDWEST REGION/BRAZIL CONTEXT

Albina Pereira de Pinho Silva* Universidade do Estado do Mato Grosso

Leandra Ines Seganfredo Santos** Universidade do Estado do Mato Grosso

Ruberval Franco Maciel ${ }^{* * *}$

\footnotetext{
${ }^{1}$ Este artigo compartilha recorte dos dados oriundos do projeto de pesquisa de Estágio Pós-doutoral ofertado pelo Programa de Pós-Graduação Stricto Sensu em Letras pela Universidade Estadual de Mato Grosso do Sul (UEMS), unidade de Campo Grande - MS

* Doutora em Educação pela UfRGS. Professora Adjunta da Universidade do Estado de Mato Grosso, Câmpus de Sinop, atua no curso de Pedagogia e nos Programas de Pós-graduação stricto sensu Mestrado Acadêmico em Letras e Mestrado Profissionalem Rede-PROFLETRAS.E-mail:albina@unemat.br.

** Doutora em Linguística Aplicada e Estudos da Linguagem (UNESP). Professora adjunta da Universidade do Estado de Mato Grosso, atua nos cursos de Pedagogia e Letras e nos Programas de Pós-graduaça (Mestrado Acadêmico em Letrase MestradoProfissionalem Rede-PROFLETRAS.E-mail: leandraines@unemat.br. 
RESUMO: Este artigo analisa práticas multiletradas viabilizadas com uso das tecnologias digitais pelos docentes de língua portuguesa (LP), egressos das turmas 1 e 2 de duas unidades de pós-graduação stricto sensu Mestrado Profissional em Letras (PROFLETRAS), situadas na região Centro Oeste do país. A busca pela melhoria das capacidades de letramentos dos estudantes de escolas brasileiras, na atualidade, traduz um dos desafios aos docentes que ingressam, sobretudo, no PROFLETRAS, dadas as amplas modificações nas práticas comunicativas. A pesquisa referencia-se nos princípios do método qualitativo-interpretativista (BORTONI-RICARDO, 2008). O corpus de análise compõe-se dos recortes de produções multiletradas viabilizadas como requisito do trabalho de conclusão (TC). Os dados da pesquisa apontam para a necessidade de o PROFLETRAS, as escolas e os professores de LP se atentarem para estudos das possibilidades de inserção das tecnologias digitais, com vistas a refletir sobre as concepções de língua/linguagem em tempos contemporâneos, em que outros perfis de leitor/escritor multiletrado caracterizam-se uma das exigências da atual sociedade.

PALAVRAS-CHAVE: Letramentos. Multiletramentos. Interfaces Digitais. Cultura Digital.

RESUMEN: Este artículo analiza prácticas de alfabetización múltiple viabilizadas con el uso de las tecnologías digitales por los docentes de lengua portuguesa (LP), egresados de los grupos 1 y 2 de dos unidades de postgrado stricto sensu Maestría Profesional en Letras (PROFLETRAS), localizadas en la región Centro Oeste del país. La búsqueda por mejorar las capacidades de Alfabetización de los estudiantes de escuelas brasileñas, en la actualidad, se traduce en uno de los desafíos para los docentes que ingresan, sobre todo, en PROFLETRAS, dadas las amplias modificaciones en las prácticas comunicativas. La investigación toma como referencia los principios del método cualitativo-interpretativo (BORTONI-RICARDO, 2008). El corpus de análisis se compone de los recortes de producciones de alfabetización múltiple viabilizadas como requisito del trabajo de grado (TG). Los datos de la investigación señalan la necesidad de que el PROFLETRAS, las escuelas y los profesores de LP presten atención a los estudios de las posibilidades de inserción de las tecnologías digitales, con miras a reflexionar sobre las concepciones de lengua/lenguaje en tiempos contemporáneos en los que otros perfiles de lector/escritor en alfabetización múltiple caracterizan uno de los requisitos de la contemporaneidad.

PALABRAS CLAVE: Alfabetización. Alfabetización Múltiple. Interfaces Digitales. Cultura Digital.

ABSTRACT: This paper analyzes Portuguese Language teacher's multiliteracy practices developed with the use of digital technologies. They are from the first and second group of two units of PROFLETRAS, a Master Degree Program, located in the Midwest region, in Brazil. The search for the improvement of Brazilian schools' students' literacy skills, nowadays, translates one of the challenges to the teachers who enter, mainly, in the PROFLETRAS, given the wide modifications in the communicative practices. It is a qualitative-interpretative research (BORTONI-RICARDO, 2008). The analysis corpus is based on the multiliteracy production requirement of the conclusion work. The data point out it is necessary to the PROFLETRAS, the schools and the Portuguese Language teachers to study the possibilities of digital technology inclusion, in order to reflect the language conceptions in contemporaneity. This time demands other reader/writer multiliteracy profiles.

KEYWORDS: Literacy. Multiliteracy. Digital Interfaces. Digital Culture.

\section{INTRODUÇÃO}

$\mathrm{Na}$ contemporaneidade, as vertiginosas transformações decorrentes da intensificação das tecnologias digitais nos diferentes contextos sociais afetaram consideravelmente as atividades humanas e, por conseguinte, as dinâmicas de comunicação, os eventos e práticas de leitura e produção de texto, o acesso, a interação e imersão com os diversos gêneros de textos em circulação social, o compartilhamento de informações, a produção de conhecimentos, dentre outras ações que mobilizam e ampliam o uso da língua/linguagem em tempos da cultura digital ou cibercultura.

Essa sociedade cada vez mais digital altera significativamente as atividades em todos os setores da vida humana. Cada dia as pessoas são mobilizadas a conviver com novos e múltiplos desafios, o que demanda delas novos acervos de conhecimentos e novos letramentos. Essa realidade afeta, principalmente, o docente de Língua Portuguesa (doravante LP), uma vez que pressupõe desse profissional abertura para novas aprendizagens e apropriação de um repertório de teorias que sinalizem práticas mais 
contextualizadas com a realidade dos estudantes da era digital e, simultaneamente, fundamentem as mudanças que a própria língua/linguagem exerce sobre as dinâmicas de uso das tecnologias e das interfaces digitais próprias da cibercultura.

A pesquisa referencia-se nos princípios do método qualitativo-interpretativista (BORTONI-RICARDO, 2008), com ênfase na análise das práticas multiletradas potencializadas com uso das tecnologias digitais no âmbito das pesquisas de trabalho conclusão (TC) e/ou dissertações dos docentes de LP, egressos da primeira turma do PROFLETRAS, de dois Programas situados na região Centro-Oeste do país, quais sejam: a Universidade do Estado de Mato Grosso (UNEMAT), câmpus universitário de Sinop-MT e a Universidade Estadual de Mato Grosso do Sul (UEMS), unidade universitária de Campo Grande-MS.

Como critério para seleção dos materiais de análise, adotamos os estudos em que os egressos do Programa propuseram pesquisa ação sobre práticas de leitura e escrita, sob a perspectiva dos multiletramentos - uma das principais bases teóricas indicada para as pesquisas realizadas no âmbito das ações do PROFLETRAS. Consideramos, ainda, como critério o fato de que as Diretrizes do Programa, em âmbito nacional, preconizam o uso crítico das tecnologias digitais para viabilizar inovações no ensino de LP, visto que "[...] espera-se que o projeto tenha característica inovadora e que criticamente envolva o uso das tecnologias digitais" (SANTOS, 2016, p. 22).

Dada essa premissa, a questão que orienta esta pesquisa é: em quais situações de ensino e como as tecnologias digitais foram inseridas nas práticas multiletradas tecidas no âmbito das pesquisas dos docentes de LP, egressos do PROFLETRAS?

Para além desta introdução, a composição do texto privilegia quatro seções. Na primeira, contextualizamos nossas itinerâncias, inquietudes, desafios, bem como a centralidade da pesquisa. Situamos, também, o PROFLETRAS como política pública educacional de formação de professores de LP em âmbito nacional; na segunda seção, discutimos o ensino de LP nas teias das interfaces digitais da cibercultura, como também os fundamentos teórico-metodológicos dos multiletramentos; na terceira seção, apresentamos o corpus de dados qualitativos e análise das práticas multiletradas tecidas com uso das tecnologias digitais, foco desta pesquisa; e, por fim, tecemos considerações finais com a defesa de que o PROFLETRAS, as escolas e os docentes de LP se atentem para as diretrizes que orientam os currículos de formação docente, sobretudo, na necessidade de examinar as potencialidades das tecnologias e interfaces digitais para refletir sobre as concepções e o ensino de língua/linguagem em tempos contemporâneos.

\section{LÓCUS DE ENUNCIAÇ̃̃O E CONTEXTUALIZACÃO DA PESQUISA}

As múltiplas itinerâncias que temos no PROFLETRAS possibilitam autênticas experiências mobilizadoras de reflexões sobre nossos papeis frente às ações de formação continuada de professores de LP e, ao mesmo tempo, nos inquieta face aos complexos desafios inerentes a necessidade de consolidar, na formação desses docentes e dos estudantes da Educação Básica, os letramentos críticos, posto que esses se constituem fontes potenciais para assunção de posturas mais críticas, por parte dos estudantes das escolas contemporâneas, ao acessar e interagir com os múltiplos eventos de leitura e escrita, enquanto práticas sociais, em ampla circulação social.

Um dos desafios que se apresentam para nós - na condição de professores-formadores do Programa -, está em articular teoria e prática nos percursos formativos, de modo que os mestrandos consigam questionar as teorias de base que fundamentam suas próprias práticas docentes, com vistas a problematizá-las e, a partir de novas formulações teórico-práticas, busquem implementálas em sala de aula, avaliar e refletir sobre as implicações desse processo na aprendizagem dos estudantes e, por fim, comuniquem os resultados alcançados no contexto da formação continuada.

Consoante essa realidade, na tessitura dos projetos de pesquisas, esses docentes são mobilizados a tecer os fundamentos teórico, conceitual e metodológico das propostas intervencionistas que originarão os diversos produtos, como os relatórios, os cadernos pedagógicos, os TC e/ou as dissertações, dentre outras inúmeras produções atinentes às especificidades de cada disciplina que compõe o Programa. 
Como já mencionado, essa realidade traduz o compromisso político do Programa e dos profissionais docentes-pesquisadores, que preocupados com os resultados do ensino de LP no país, aceitaram ampliar suas experiências formadoras, sobretudo, no campo do ensino e da pesquisa, em atenção à proposta, aos objetivos e metas preconizadas pelo PROFLETRAS no que diz respeito à formação de professores de LP em âmbito nacional.

\section{O PROFLETRAS NA FORMAÇÃO DE PROFESSORES DE LÍNGUA PORTUGUESA}

No atual cenário das políticas públicas educacionais são inúmeros os Programas instituídos em atenção às questões relativas aos resultados das avaliações externas que apontam o expressivo índice de estudantes que se encontram em anos iniciais e finais do ensino fundamental e que ainda não consolidaram as competências de leitura, compreensão e produção de textos. O fato desses estudantes não apresentarem autonomia para ler e interpretar competentemente os mais variados gêneros de textos tem mobilizado a criação de políticas públicas, que, por sua vez, desencadeiam uma série de implicações que recaem sobre as agências formadoras, sobre a atuação dos formadores-pesquisadores das Instituições de Ensino Superior (IES), sobre a função das escolas - enquanto agência de letramento -, e de seus profissionais docentes, principalmente, aos que atuam na área de Letras e da Educação.

Diante desse cenário, docentes-pesquisadores da área de Letras e Linguística de diferentes IES do país assumiram essa causa com motivação, coragem, compromisso social e ousadia. Dessa atitude comprometida é que o PROFLETRAS foi idealizado, com vistas a trilhar o caminho pela busca da tão sonhada perspectiva de formar professor-pesquisador de seu próprio fazer docente frente à complexidade e dilemas do mundo contemporâneo em constante transformação (SILVA; SANTOS, 2018, no prelo).

O PROFLETRAS é um curso de Pós-graduação Stricto Sensu com oferta em rede nacional, tem participação de cinquenta instituições de ensino superior alocadas no Sistema Universidade Aberta do Brasil (UAB), cujo objetivo, a médio prazo, centra na formação de professores de LP que atuam em anos finais do ensino fundamental em diferentes sistemas escolares de todo o território nacional (CAPES, 2013). Com o intuito de minimizar os baixos índices de letramento dos estudantes, como assevera Santos (2016).

Isso posto, o PROFLETRAS tem como propósito fortalecer os projetos, propostas e currículos de formação inicial e continuada de professores de LP, com foco em ações formativas contextualizadas que favoreçam a esses profissionais docentes a apropriação de novas teorias acerca do(s) letramento(s), de natureza linguístico-discursivo, no intuito de engendrar inovações nas práticas de ensino, em atenção às necessidades de qualificar socialmente a educação ofertada nas escolas públicas brasileiras e, por conseguinte, consolidar melhorias nos processos de apropriação dos repertórios de competências linguístico-discursivas a que os estudantes têm direito.

Além disso, a ideia que baliza o Programa está na criação de redes voltadas para a produção de conhecimentos oriunda de ações colaborativas entre as Universidades e as escolas de Educação Básica. Esse se constitui um dos desafios em busca da ruptura do distanciamento que há entre a ciência produzida e praticada na universidade em relação ao acervo de conhecimentos e experiências pedagógicas produzido e mobilizado pelos docentes nas salas de aulas das escolas de Educação Básica. Todavia, na atual conjuntura social, essa concepção não tem mais sustentação, uma vez que a Educação como espaço social de aprendizagem é um compromisso das instituições formadoras que buscam por meio dos processos educacionais promover a inclusão social e emancipação política dos cidadãos/protagonistas que, por via da educação, esperam validar seus direitos de aprendizagem garantidos na própria Legislação.

Os professores de LP - ingressantes no Programa -, são mobilizados a propor um projeto de pesquisa de natureza intervencionista, cujo objeto de análise incide sobre os expressivos índices de estudantes que se encontram com as competências linguísticas aquém da esperada, conforme apontam resultados de avaliações externas. Esse desafio de aliar teoria e prática e, simultaneamente, ter a possibilidade de constituir a identidade como professor-pesquisador da sua própria prática pedagógica caracteriza-se umas das dimensões de inovação na área dos estudos da linguagem preconizada na proposta. 
Feita essa breve contextualização, este texto tem como centralidade a análise das práticas multiletradas aliadas ao uso das tecnologias digitais produzidas no contexto das pesquisas dos professores de LP, egressos da primeira turma do PROFLETRAS de duas unidades alocadas na região Centro-Oeste.

\section{ENSINO DE LÍNGUA PORTUGUESA NAS TEIAS DAS INTERFACES DIGITAIS DA CIBERCULTURA}

No advento da escola moderna os textos impressos e os materiais didáticos tiveram seu apogeu, assim como o uso das mídias de massa e o ensino de leitura e produção de textos pautaram-se na perspectiva de "um ensino mecânico e escolarizado de práticas de letramento digital, com pouca alteração nos modos de construir conhecimentos na escola. [...]”, como argumenta Bunzen (2015, p. 109). O mesmo autor pondera, ainda, que: "[...] A escolha de textos impressos e clássicos da literatura aponta necessariamente para uma forma escolar que prioriza um ensino do "ler" sistematizado, formalizado, obrigatório, que leva em consideração determinados gêneros, textos e autores (e não outros!), enfocando necessariamente atividades e tarefas específicas”.

Esses argumentos sinalizam que tal modo de operacionalização do ensino de leitura na escola necessita passar por profundas revisões e reflexões, visto que a sociedade tem passado por inúmeras mudanças históricas, sociais, políticas, econômicas e culturais em detrimento do processo de globalização. Dentre elas, as descobertas tecnológicas caracterizam as mudanças que revolucionaram a atual sociedade, uma vez que, segundo Castells (1999), surgiram novos meios comunicacionais e as tecnologias da informação e comunicação, as chamadas TIC. Foram essas rápidas mudanças, nos dizeres do autor, que possibilitaram o acesso à informação e comunicação em qualquer lugar e a qualquer tempo, por meio do acesso e conectividade com a rede de internet. Essas transformações sociais e, sobretudo, culturais desencadearam profundas mudanças no campo dos estudos da linguagem, visto que ampliaram o universo das práticas de Letramentos.

Bunzen (2015, p. 108-109) corrobora esses argumentos ao ponderar que é necessário pensar sobre as práticas de letramentos face ao momento histórico porque passam a sociedade, a educação, a escola e, sobretudo, é preciso refletir que nem todas as interações e aprendizagens das múltiplas linguagens e letramentos digitais acontecem no sistema escolarizado, até mesmo porque:

[...] estamos vivenciando um marco histórico em que os sujeitos interagem com diferentes tecnologias, mídias e gêneros sem quase nenhuma interferência do processo de escolarização. [...] Muito provavelmente grande parte de tais aprendizagens ocorreram de forma pouco sistemática e fora do contexto escolar, isto é, distante das práticas, eventos, crenças e valores, que perpassam o processo de escolarização. Ao mesmo tempo, os sujeitos podem usar computadores, celulares, controle remoto, tablets/ipads, caixas eletrônicos e máquinas fotográficas digitais de maneira pouco crítica e sem uma reflexão mais consciente sobre o papel das múltiplas linguagens nos diversos tipos de interação (não) humana que participam.

Essas profundas alterações nas dinâmicas de interagir e se apropriar das múltiplas linguagens, das mais variadas interfaces digitais e repertórios de novos letramentos caracterizam-se consequências do processo de globalização e da acelerada intensificação das TIC na sociedade. Giddens (2002) assegura que vivemos em um mundo em permanente descontrole, porque os indivíduos perderam a segurança, a ordem, o controle, valores amplamente privilegiados na era da modernidade. Esse movimento caracteriza o que Castells (1999) denominou de desordem global, visto que as inúmeras mudanças afetaram as relações sociais, bem como, as atividades humanas em seus diferentes modos de ser e de viver, de trabalhar, de buscar e acessar informações e, sobretudo, de produzir novos conhecimentos.

Nesse contexto, a educação é um espaço social em que esses efeitos das complexas transformações alteraram não somente a dinâmica do trabalho docente, mas ainda os modos de acesso e interação dos estudantes com os eventos e práticas de leitura e escrita, sejam esses os letramentos escolares ou vernaculares ${ }^{2}$. Esse cenário de mudanças sociais gera, segundo Rojo (2009, p. 106-107), profundas

\footnotetext{
2 "Os chamados letramentos 'vernaculares' não são regulados, controlados ou sistematizados por instituições ou organizações sociais, mas têm sua origem na vida cotidiana, nas culturas locais. Como tal, frequentemente são desvalorizados ou desprezados pela cultura oficial e são práticas, muitas vezes, de resistência”. (ROJO, 2009, p. 102-103, grifos da autora).
} 
implicações no trabalho pedagógico promovido nas escolas, enquanto agência de letramentos, até mesmo porque: "Essas mudanças fazem ver a escola de hoje como um universo onde convivem letramentos múltiplos e muito diferenciados, cotidianos e institucionais, valorizados e não valorizados, locais, globais e universais, vernaculares e autônomos, sempre em contato e em conflito, sendo alguns rejeitados ou ignorados e apagados e outros constantemente enfatizados".

Aprender a conviver com as múltiplas realidades demanda do professor de LP a constituição de um repertório de conhecimentos pautada em novas teorias e concepções de aprendizagem da língua materna, com vistas a engendrar novas práticas pedagógicas que potencializem a criação humana e, ao mesmo tempo, privilegiem situações de aprendizagem da língua, a convergência, cada vez mais forte, das tecnologias digitais a fim de envolver os estudantes - com perfis próprios dos tempos ciberculturais - em práticas de multiletramentos, para que esses se apropriem dos letramentos críticos e assumam atitudes responsivas ativas (BAKHTIN, 2010) frente às diferentes esferas de circulação de discursos produzidos nas mais variadas situações sociais de uso da língua.

\section{PEDAGOGIA DOS MULTILETRAMENTOS E O USO DAS TECNOLOGIAS DIGITAIS}

Nesta seção abordamos a dimensão conceitual da teoria dos multiletramentos, suas principais características e os possíveis dimensionamentos necessários às práticas de leitura e escrita (letramentos) aliadas aos desafios de vislumbrar novas possibilidades e viabilidade de uso das tecnologias digitais na tessitura de práticas multiletradas na escola.

A pedagogia dos multiletramentos, nos dizeres de Rojo (2012; 2013), surge com a preocupação de abordar a diversidade cultural e a diversidade de linguagem na escola, cujo conceito aponta o prefixo "multi", para dois tipos de "múltiplos", que as práticas de letramento contemporâneas agregam. Por um lado, multiplicidade de linguagens, semioses e integração de tecnologias digitais na criação de significação para textos multimodais contemporâneos e, por outro lado, a pluralidade e diversidade cultural produzidas pelos autores/leitores da contemporaneidade a essa criação de significação.

No paradigma da modernidade, os textos impressos e os materiais didáticos tiveram seu apogeu no ensino de LP, assim como o uso das mídias analógicas e a produção de textos lineares, com prioridade na estrutura formal da língua culta padrão, como bem argumenta Rojo (2013, p. 16):

\footnotetext{
Na abordagem da leitura e da produção de textos escritos, são priorizados o trabalho temática e estrutural ou formal, ficando as abordagens discursivas ou a réplica ativa em segundo plano. A prioridade para a norma e a forma também é vista nos trabalhos de reflexão sobre a língua, pautados na gramática normativa e baseados nas formas cultas da língua padrão, nunca explorando diferentes variedades sociais ou geográficas da língua efetivamente em uso.
}

Esses argumentos elucidam como as propostas de letramentos praticadas nas escolas ignoram e ocultam as exigências de novos letramentos em atenção as mudanças inerentes aos meios de comunicação e à circulação da informação. Essa concepção de linguagem adotada no paradigma da modernidade contrapõe a concepção de língua/linguagem preconizada por Bakhtin (2010, p. 268). Para o estudioso, há uma ampla interlocução entre linguagem, diálogo e vida. Reconhecer a dimensão dialógica da linguagem implica concebê-la vinculada às múltiplas interações discursivas resultantes de condições sociais e históricas, as quais, por sua vez, são heterogêneas e dialógicas, porque agrega diferentes variedades linguísticas e culturais de uma nação (SILVA, 2013).

Conceber a linguagem, sob a perspectiva da teoria enunciativa do Círculo de Bakhtin, significa reconhecer, segundo Rojo (2009), que face a intensificação e a diversificação da circulação da informação nos meios de comunicação analógicos e digitais, um dos objetivos da escola está em possibilitar que os estudantes participem das diversas práticas sociais que se valem "[...] da leitura e da escrita (letramentos) da vida da cidade, sob uma perspectiva ética, crítica e democrática” [grifos da autora] (ROJO, 2009, p. 107). Os multiletramentos ou letramentos múltiplos, conforme Rojo (2009), não ignoram nem apagam os letramentos das culturas locais de seus agentes (professores, alunos, comunidade escolar) e colocando-os em contato com os letramentos valorizados. 
A pedagogia dos multiletramentos caracteriza-se como pesquisas recentes na área da linguagem e da educação, como bem asseveram Maciel e Parreira Ono (2017, p. 7):

\begin{abstract}
Nessa perspectiva, pesquisas recentes no campo da linguagem e da educação, como por exemplo, os estudos sobre novos letramentos e multiletramentos propõem ressignificações das práticas de letramentos escolares e não escolares. Segundo essa vertente, parte-se do pressuposto de que sempre fomos multimodais. Nesse raciocínio, podemos dizer que desde as culturas ágrafas, os sentidos sempre foram representados por várias modalidades e, portanto, sempre fomos multimodais. A multimodalidade está presente nas figuras rupestres, nas danças de comunidades indígenas isoladas, nos movimentos de batalhas do movimento hip hop, na ausência de uma pessoa falecida ao se comparar uma foto antiga e uma atual de família, nos gestos de concordância ou negação, no silêncio de um olhar triste, no cheiro de um perfume de uma pessoa conhecida ou um texto que vem à mente de uma comida de infância a partir do cheiro, os intertextos presentes em um videoclipe, entre outros. Todos esses exemplos são manifestações de linguagens, são textos com representações situadas de sentidos compostos por várias modalidades.
\end{abstract}

Vivemos na era das linguagens líquidas, por isso Santaella (2007) assegura que se faz necessário ampliar as lentes e admitir que os estudantes da contemporaneidade são nativos da era digital. Essa assertiva, por sua vez, sugere novos paradigmas de aprendizagens de línguas, sobretudo, de língua materna. Diante das inúmeras interfaces digitais, os estudantes da era digital conseguem, a partir da convergência das mídias digitais, produzir novas linguagens e coleções de textos, por meio de práticas colaborativas, em ambientes digitais de rede.

\title{
6 PRÁTICAS MULTILETRADAS POTENCIALIZADAS COM USO DAS TECNOLOGIAS DIGITAIS: ANÁLISE DE DUAS REALIDADES DO PROFLETRAS
}

Esta seção do texto apresenta o corpus de análise, que se constitui das práticas multiletradas que integram os TC e as dissertações dos professores de LP, egressos da primeira turma do PROFLETRAS de dois Programas de Mestrado da região Centro-Oeste do país mencionados anteriormente.

Para composição do corpus de análise, fizemos download no portal das IES, das vinte (20) dissertações defendidas, em 2015, pela primeira turma do PROFLETRAS na UEMS e dezoito (18) TC defendidos na UNEMAT no mesmo ano. Ao todo, examinamos trinta e oito (38) pesquisas. Após a leitura dos resumos, agrupamos as pesquisas por conteúdos temáticos e, posteriormente, criamos as categorias assim descritas: (1) propostas que são de natureza pesquisa ação, mas não apresentam práticas multiletradas; (2) pesquisas interventivas na perspectiva dos multiletramentos; (3) pesquisas interventivas na perspectiva dos multiletramentos aliados ao uso das tecnologias digitais.

O trabalho pedagógico sob a ótica dos multiletramentos, segundo Rojo (2012) e Coscarelli e Kerschi (2016), privilegia duas perspectivas: o uso de novas tecnologias e a diversidade linguística e cultural, em que a prática social local dialoga com o global. Todavia, vale destacar, também, que as práticas de multiletramentos, segundo Rojo (2012), podem ou não integrar a utilização das novas tecnologias, mas geralmente pressupõe o uso de mídias digitais e interfaces interativas, nosso foco de análise são aquelas práticas de leitura e escrita potencializadas pelo uso das tecnologias digitais.

A $1^{\text {a }}$ turma do PROFLETRAS da UEMS teve vinte (20) ingressantes e o mesmo número de concluintes. Das vinte dissertações defendidas pelos docentes de LP, egressos da UEMS, em 2015, treze (13) dissertações correspondem a 65\% das pesquisas interventivas na perspectiva dos multiletramentos e sete (07) caracteriza $35 \%$ das pesquisas, sob a perspectiva dos multiletramentos aliados ao uso das tecnologias digitais.

Na unidade do PROFLETRAS da UNEMAT, câmpus de Sinop, dos dezoito (18) docentes egressos do Programa, 100\% propuseram pesquisas interventivas, sob a perspectiva dos multiletramentos aliados ao uso das tecnologias digitais. 
Como já mencionado, de um universo de vinte dissertações defendidas na UEMS, em 2015, seis (07) integraram nas práticas multiletradas o uso das tecnologias digitais e treze (13) caracterizam-se práticas de multiletramentos, mas as tecnologias não foram utilizadas na viabilidade da pesquisa ação.

A pesquisa realizada por Gonzalez Além (2015) promoveu uma experiência de produção de textos, a fim de instigar a capacidade crítica por meio da análise de fatos ou textos, ampliar a capacidade de interação, como também familiarizar os estudantes com o gênero blog. Nesse percurso, a docente privilegiou a crônica - gênero híbrido com características do jornalismo e da literatura. Para tal, utilizou o blog como interface digital para facilitar as interações comunicativas, o acesso e compartilhamento de dez crônicas disponibilizadas como material de estudos e, sobretudo, para favorecer o processo de produção de crônicas, como atividade de produção final.

A pesquisa de Santos (2015) apresenta a análise do uso de gêneros textuais orais e escritos nas aulas de LP, por meio de utilização do recurso do hipertexto em um blog para o trabalho com diversos gêneros textuais orais e escritos. A criação do blog justificou-se na proposta, segundo a pesquisadora, para os educandos fazerem "o registro das atividades realizadas, bem como para a postagem de links para textos, vídeos, imagens e todo o conteúdo que se referir à utilização do hipertexto na realização de atividades de leitura $\mathrm{e}$ escrita dos diversos gêneros textuais orais e escritos" (SANTOS, 2015, p. 8).

Brito (2015), em seus estudos, possibilitou que os estudantes se apropriassem de uma postura investigativa de valorização como seres humanos, elevando-lhes a autoestima e, ao mesmo tempo, criando situações diferenciadas que contribuíssem para o aprimoramento dos conhecimentos produzidos durante a pesquisa inerentes a hábitos locais, costumes alimentícios, arte, literatura, história do nascimento e formação dos municípios, bem como os estudos de manifestações culturais. Embora, a autora tenha mencionado na proposta metodológica o uso de recursos didáticos como: aparelho de som, CDs de músicas regionais, televisão, DVDs de filmes variados dentro da temática regional, e as tecnologias de informática, não descreve em que situações de ensino e como esses recursos foram utilizados como suporte pedagógico.

A pesquisa de Teixeira (2015) primou pelos eixos temáticos leitura, escrita e produção textual. Para conhecer as necessidades dos estudantes, a pesquisadora usou as tecnologias móveis (aparelhos celulares) como suporte para gravação dos textos orais formais, precisamente a oralização da escrita. A proposta compôs-se de atividades de oralidade a partir do texto escrito e privilegiou desde a contação de histórias ao gênero simulado. O conto literário sob o efeito da releitura possibilitou a marca de seu recriador, evidenciada na gravação da voz, por meio do celular, tecnologia socialmente constituída.

A proposta de Viana (2015) compartilhou o trabalho com os gêneros dos textos jornalísticos mediante práticas de leitura, interpretação e produção de textos do suporte jornal. As atividades com textos tiveram início em sala de aula, mas se estenderam para o laboratório de informática devido ser este um ambiente com recursos disponíveis na escola para uso de professores e alunos. Como a proposta envolveu a leitura de jornais on line e a criação de jornais pelos estudantes, esses tiveram de realizar leituras e consultas na internet. Além disso, os estudantes utilizaram o editor de texto para edição, produção e digitalização dos textos.

O trabalho de Souza (2015) consistiu no aprimoramento da formação de leitores, por meio de leituras dos romances do Pedro Bandeira e atividades de retextualização, que se deram nos espaços da biblioteca e no laboratório de informática da escola. Como primeiras atividades, os estudantes produziram tirinhas com suporte do programa Make Beliefs Comix e as histórias em quadrinhos foram produzidas manualmente por eles, em sala de aula. Com os textos prontos, as demais aulas aconteceram no laboratório de informática. Nessas aulas, a docente e os estudantes tiveram a colaboração da profissional responsável pelo ambiente informatizado que os auxiliou na utilização do editor de desenho (Paint) para criação dos principais personagens da história, os quais, posteriormente, foram inseridos nas histórias em quadrinhos (HQs) editadas e produzidas no Comix Book Creator. Este editor online possibilitou o acréscimo de detalhes e recursos visuais diversos às histórias. Como produto final, as HQs foram impressas em um banner e organizadas em vídeo, editado na ferramenta Movie Maker, que foi apresentado na feira literária da escola. 
Torales (2016) propôs atividades de leitura, em que os estudantes criaram suas próprias produções literárias, como poemas, crônicas, anedotas, resumos e indicações de obras e, posteriormente, houve a confecção de um jornal literário com os textos produzidos pelos estudantes. O estudo demonstra que as tecnologias digitais foram utilizadas para realização de pesquisas na internet para acessar notícias literárias nacionais e do Estado de Mato Grosso do Sul, como lançamento de obras e divulgação de concursos, prêmios literários e eventos culturais. Todavia, a pesquisadora assevera que os educandos "tiveram muita dificuldade para pesquisar o que fora proposto, trazendo outros assuntos e até notícias desatualizadas. [...]” (2016, p. 98). Diante disso, houve a necessidade de colaboração e orientação da professora no desenvolvimento dessa atividade.

Esse fato reafirma que as novas práticas sociais de letramento demandam interlocutores que saibam operacionalizar e interagir com os meios de comunicação digitais, até mesmo porque, conforme assevera Kalazantis e Cope (2006[2000]), novas tecnologias pressupõem novos letramentos. Isso mobiliza, na contemporaneidade, a compreensão de que as práticas de leitura e produção de textos estão ainda mais interconectadas, uma vez que "[...] os novos suportes de textos permitem usos, manuseios e intervenções do leitor infinitamente mais numerosos e mais livres do que qualquer uma das formas antigas do livro" (CHARTIER, 1997, p. 88). Esses argumentos reafirmam a defesa de que a escola, enquanto agência de letramentos (ROJO, 2009), necessita se atentar para criação de ambiências de aprendizagem favoráveis às práticas de letramentos digitais e, por conseguinte, para a inclusão dos estudantes na cultura digital.

O conjunto de dados qualitativos referentes às pesquisas dos docentes de LP - egressos do PROFLETRAS da UEMS -, compartilhadas neste texto, suscitam reflexões que se respaldam nas ideias de Silva (2010) ao asseverar que os educadores estão diante do desafio de aprender sob a influência das tecnologias digitais próprias da cultura contemporânea, porque "[...] em sala de aula essa aprendizagem é interativa porque ocorre mediante participação, bidirecionalidade e multiplicidade de conexões, portanto, mediante simulações/experimentação. [...]" (SILVA, 2010, p. 90).

\subsection{PRÁTICAS MULTILETRADAS E O USO DAS TECNOLOGIAS DIGITAIS: A REALIDADE DO PROFLETRAS DA UNEMAT}

Como mencionado anteriormente, todos os docentes de LP, egressos da primeira turma do PROFLETRAS da UNEMAT, integraram em suas propostas intervencionistas o uso das tecnologias digitais para produção de práticas multiletradas no processo de aprendizagem dos estudantes dos anos finais do ensino fundamental, como preconizam as diretrizes que orientam as ações do Programa em âmbito nacional. Dada esta realidade, agrupamos os TC por blocos temáticos.

Silva (2015), Babinski (2015) e Freire (2015) promoveram em seus estudos práticas de letramento literário, por meio dos gêneros poemas, contos africanos contextualizados com as práticas sociais dos próprios estudantes. As propostas intervencionistas favoreceram aos estudantes a compreensão e reflexão sobre a leitura, a interpretação e a produção textual mediados pelos recursos das tecnologias. Nesse processo, os diferentes gêneros literários aliados ao uso das tecnologias se mostraram fontes potenciais para o letramento e a humanização dos alunos-adolescentes em processo de formação leitora consoante a produção de infopoemas, hipercontos em suportes de ambientes digitais. Além disso, as propostas intervencionistas privilegiaram práticas de leitura literária e escrita, a interação com a multiplicidades de linguagens, a inclusão dos estudantes com as práticas do letramento digital e literário para potencializar a produção do conhecimento e a própria humanização.

Sob essa mesma lógica, Scrimim (2015), Cervieri (2015) e Rocha (2015) realizaram pesquisas sobre as práticas de letramentos literários, para potencializar atividades de leituras, compreensão, análises de obras literárias e produção de textos por meio de gêneros literários associados ao viés dos multiletramentos. Nesse processo de interação entre leitor e o texto literário, houve valorização de aspectos como criatividade, intenção estética, despertar da sensibilidade e senso crítico dos educandos em relação ao texto literário. Por isso, houve situações favoráveis à apreciação autônoma e espontânea de obras literárias. Nas práticas de escrita decorrentes das vivências com o letramento literário, houve a utilização do laboratório de informática pelos educandos para digitalização dos seus textos que, posteriormente, foram publicados em sites da internet para compartilhamento e promoção de maior visibilidade das produções na rede. 
As práticas de leitura e escrita aliadas à utilização da rede social (facebook) como meio de comunicação digital para exposição de produções textuais dos estudantes, caracteriza-se, segundo Scrimim (2015), uma interface potencializadora do processo de formação de leitores assíduos e competentes e se justifica porque possibilita que o professor exerça influência sobre a formação leitora e escritora dos educandos no que se refere às leituras de clássicos, tão esquecidos, na atualidade, pela escola.

Santos e Santos (2016, p. 264-265) reafirmam essa assertiva ao asseverarem que:

\begin{abstract}
A preocupação emerge com maior vigor do fato de que a escola privilegia, ainda, um modelo de estudo da Língua Portuguesa desvinculado da Literatura como se esta não pertencesse ao conjunto dos bens culturais de um povo falante de determinada língua. A gramática ainda ocupa boa parte das aulas em decorrência da necessidade de cumprimento de currículos estruturalistas que não levam à apropriação de fato das práticas de leitura e escrita na perspectiva do(s) letramento(s). Aliado a esse aspecto, encontram-se docentes com dificuldade de lidar com a linguagem literária, uma vez que suas características exigem um cuidado maior na elaboração do material e uma leitura mais demorada para compreender os "bosques" pelos quais o leitor deverá trilhar.
\end{abstract}

Motivada pelos desafios apresentados pelos estudantes da modalidade de Educação de Jovens e Adultos (EJA), no que diz respeito às práticas de leitura e compreensão de texto, na perspectiva dos letramentos literários, Malaguti (2015) privilegiou como centralidade de sua pesquisa a leitura de textos memorialísticos no processo de formação do leitor dessa modalidade de ensino. Com relação ao uso das tecnologias digitais, a autora descreve, na parte metodológica, o uso do laboratório de informática para os estudantes realizarem leitura de crônicas na internet, como também para digitalizar lacunas deixadas no texto. Esta realidade nos mobiliza a questionar: será que os ambientes digitais on-line poderiam potencializar outras possibilidades de leitura e escrita por parte dos estudantes da EJA?

Os estudos de Scrimim (2015), Cervieri (2015) e Rocha (2015) evidenciam que os ambientes digitais on-line constituem-se espaços fecundos para produção de conhecimentos, dada a instantaneidade de acesso às informações disponíveis na rede, o que tem significativamente acelerado as atuais transformações socioculturais. Os meios de comunicação eletrônicos e as tecnologias digitais da informação e comunicação (TDIC) exercem profundas alterações nas dinâmicas de leitura mediante os textos digitais em ampla circulação social em suportes digitais e interativos. Essas interferências nos modos de acessar, interagir e ler esses múltiplos textos em suportes digitais suscitam pensar as práticas de leitura, compreensão e produção de textos mediadas em suportes de ambientes ciberculturais, visto que nos dizeres de Lévy (1993), o ciberespaço caracteriza-se o início da era cibercultural, que se deu no final do século XX e início do XXI. Para o autor, o ciberespaço e a cibercultura desencadearam inovações nos atos de leitura e, por conseguinte, novas exigências de perfil de leitor e escritor frente aos múltiplos papéis que passa a assumir a partir das demandas oriundas das invenções e avanços tecnológicos.

Kress (2003) pondera que, na atualidade, vivemos uma realidade dominada cada vez mais pelas imagens como práticas comunicativas. Nesse processo, Cani e Coscarelli (2016, p. 24) asseveram que, na era multimodal, é preciso considerar o conceito de design, com vistas a instigar os estudantes a perceber "as várias informações, valores e ideologias que são transmitidas pelas imagens e pelos recursos não verbais presentes nos textos para agir criticamente sobre eles".

Sob essa concepção de linguagem, Oliveira (2015) e Costa (2015) promoveram em suas pesquisas práticas de leitura e escrita de textos multimodais em suportes de redes sociais na internet (facebook), com objetivos de compreender a produção de sentidos no processo de leitura de textos multimodais em ambiente digital, na interação autor-texto-leitor. Esse processo compreendeu alguns dos principais gêneros que circulam na internet como: a charge, a tira, a foto legendada, a enquete e a entrevista jornalística, dentre outros, que foram aliados ao uso das tecnologias disponíveis no laboratório de informática da escola, como também, os dispositivos móveis (aparelhos celulares) dos estudantes como suportes, sob a perspectiva de utilização pedagógica. Nesse percurso, os estudantes interagiram com os gêneros multimodais nas atividades de leitura, compreensão, análise e escrita, cujos resultados das produções foram compartilhados na rede social da internet, uma vez que essa interface digital se caracteriza meio de circulação e socialização dos textos que os estudantes costumam interagir e, frequentemente, estão conectados. 
Essas experiências ilustram bem o que Canclini (2008, p. 52) argumenta sobre a dimensão multimodal da comunicação possibilitada pela interatividade das interfaces próprias da cultura digital, ao ponderar que:

A comunicação digital, especialmente a de caráter móvel por meio dos celulares, proporciona, ao mesmo tempo, interação interna e deslocalização, conhecimentos e novas dúvidas. O caráter multimodal da comunicação sem fio modifica as formas, antes separadas, de consumo e interação, ao combiná-las num mesmo aparelho: o celular permite marcar compromissos presenciais, substituí-los, mandar emails ou mensagens instantâneas, lê-los ou ouvi-los, conectar-se com informação e diversão em textos e imagens, arquivar ou eliminar a história dos encontros pessoais.

Uma dentre as inúmeras defesas ao se ocupar do trabalho com os gêneros discursivos em sala de aula, está o desafio de mobilizar os estudantes a se apropriar de competências linguístico-discursiva, com vistas a assumir posições críticas, aprender a produzir significados e a fazer escolhas éticas frente aos discursos hegemônicos do mundo altamente semiotizado da globalização (ROJO, 2009).

Com essa preocupação, Silva (2015), Becker (2015) e Oliveira (2015) privilegiaram em processos de autoria aliados às teorias dos multiletramentos. Com base em gêneros emergentes, os autores promoveram atividades didáticas a fim de favorecer o processo de constituição autoral dos estudantes. Nesse itinerário intervencionista, a utilização de interfaces digitais on-line se mostrou fontes potenciais para que esses, na posição sujeitos-autores, produzissem gêneros discursivos situados com seus contextos social e histórico. As práticas de oralidade e escrita de gêneros discursivos possibilitaram a produção do gênero digital e-book como possibilidade de letramento digital, com enfoque em práticas de multiletramentos. O percurso da intervenção didática e análise dos dados evidenciam que houve a ampliação do nível de escrita, leitura, oralidade, articulação entre escrita e imagem, o que implica dizer que todas as iniciativas com o propósito de potencializar o uso das diferentes linguagens são bem vindas ao espaço escolar, tendo em vista a busca por uma educação de melhor qualidade.

Dias Antônio (2015) e Souza (2015) discutem, também, o processo de autoria nas produções textuais orais e escritas, sob a perspectiva dos multiletramentos potencializados pelo uso das tecnologias, mais notadamente ao uso da rádio escolar e facebook da rádio escolar, denominada como Radioface, visto que esse favorece e incentiva a pesquisa, o desenvolvimento de produções textuais orais e escritas, como situações reais de comunicação, produzem aprendizagens socialmente significativas em que o processo educativo se alicerça no protagonismo dos educandos, com vistas a consolidar a interação entre a escola e a comunidade. Para efetividade da proposta, os gêneros notícia radiofônica, a entrevista, a exposição oral foram privilegiados nos processos, sob a compreensão de linguagem concebida como prática social.

Weber (2015) e Mazolini (2015) por meio de propostas pautadas em práticas de leitura e produção de textos multimodais com suporte das tecnologias digitais, sob o viés teórico-metodológico dos multiletramentos e do trabalho colaborativo, proporcionaram situações de aprendizagem em que as atividades de uso da linguagem potencializaram a autonomia e autoria dos aprendizes, principalmente, quando utilizaram os recursos das tecnologias e interfaces digitais interativos da Web (1.0 e 2.0). Nesse processo de produção colaborativa e negociação entre os envolvidos, a autonomia, a autoria, a criação e a co-criação se manifestam e são amplamente valorizadas. Os estudantes foram mobilizados a refletir sobre suas histórias de vidas e identidade(s) sociocultural(is), mediante uma concepção autoral, em que, consoante trocas colaborativas e negociadas, se engajaram na produção de diferentes gêneros para composição de uma revista escolar, bem como, na criação de um blog para compartilhar ações da escola e, por conseguinte, potencializar maior interação entre a comunidade escolar e demais internautas da rede.

Saboia (2015) partilha resultados de uma intervenção pedagógica em torno dos gêneros discursivos propaganda e campanha publicitária em cartazes. Assim, as múltiplas situações de aprendizagem privilegiaram diversos gêneros discursivos com temática voltada para a propaganda, textos não verbais como imagens, vídeos, filmes, acesso a sites da internet, dentre outros elementos que compuseram o conjunto de atividades.

A proposta de ensino de Farias (2015) compreendeu atividades de pesquisas, reflexões e análises discursivas de cartazes. Para geração do produto final da pesquisa houve a criação de um "site" pelos estudantes. Esse privilegiou os múltiplos cruzamentos de informação 
inerente à temática do trabalho. Nos dizeres do autor, "o suporte discursivo pretende ser, e tem mostrado ser, efetivamente, um instrumento de engajar alunos e professores em um uso da internet voltado para o processo educacional, estimulando a pesquisa, o pensamento crítico, o desenvolvimento de professores, a produção de materiais e o protagonismo juvenil” (FARIAS, 2015, p. 07). Em linhas gerais, a criação da página na internet teve como ponto de partida a definição de uma temática e objetivos sugeridos pelo próprio docente, a partir de uma pesquisa inicial com a organização dos assuntos selecionados por meio de links para facilitar a consulta e pesquisa dos estudantes. Nesse percurso de trabalho em grupos, os estudantes assumiram o protagonismo diante dos diferentes papéis de "especialistas", com vistas a potencializar as trocas de ideias. Tanto o material de apoio disponibilizado para consulta e pesquisa, como os resultados das produções textuais dos estudantes foram publicados na web.

Segundo Moita Lopes e Rojo (2004, p. 17), os letramentos multissemióticos integram a lista de atuais necessidades relacionadas “à participação social cidadã e à inserção no universo do trabalho”. Para Rojo (2009), essas inúmeras demandas que a sociedade contemporânea apresenta à escola, por certo, ampliarão consideravelmente a multiplicidade de práticas e textos que nela devem circular e ser abordados.

\section{CONSIDERAÇÕES FINAIS}

As pesquisas desenvolvidas pelos docentes egressos da $1^{\text {a }}$ turma do PROFLETRAS das duas unidades em estudo demonstram que a integração das tecnologias digitais nos processos de (re)significar as práticas multiletradas pressupõe uma composição de ambiente formativo com atividades presencial e on-line (híbrido), por isso agrega convergência de mídias hipertextuais que favoreçam processos de leitura e escrita em que haja negociações, trocas dialógicas, o pensar coletivo, a criação/autoria e produção de novas linguagens, visto que o conhecimento constituído "no aparato permite que este seja capaz não apenas de estender habilidades sensoriais (isso é óbvio), mas o habilita a estender a capacidade humana de produzir linguagens. [...]. A mediação é mérito da linguagem e não estritamente do equipamento" (SANTAELLA, 2008, p. 206).

No dizer da autora, a capacidade humana de produzir linguagens é potencializada quando é mediada pelas interfaces e tecnologias digitais, principalmente, quando essas são integradas tanto na formação dos professores quanto dos estudantes para novas práticas de letramentos, o que implica, consoante Rojo (2013, p. 07), "[...] a integração de semioses, o hipertexto, a garantia de um espaço para autoria e para a interação, a circulação de discursos polifônicos num mesmo ciberespaço, com a distância de um clique, desenham novas práticas de letramentos na hipermídia. [...]".

Rojo (2013, p. 07) defende, ainda, que se faz necessário formar os professores “[...] para um funcionamento da sociedade cada vez mais digital e também para buscar no ciberespaço um lugar para se encontrar, de maneira crítica, com diferenças e identidades múltiplas”, posto que as mudanças decorrentes do processo de globalização e das tecnologias abrem novas possibilidades e objetos de pesquisas na área da linguística e da linguística aplicada, até porque os novos letramentos são híbridos, fronteiriços, por isso múltiplos e diferenciados, cotidianos e institucionais, valorizados e não-valorizados, locais e globais (ROJO, 2009). Diante dessa realidade, na condição de professores - agentes do letramento -, temos o compromisso de promover práticas multiletradas em que os diferentes meios de comunicação da contemporaneidade sejam integrados para produção de novos significados às práticas sociais de letramentos na escola.

Ao observar os modos como as tecnologias digitais foram inseridas nas pesquisas dos docentes egressos da $1^{\text {a }}$ turma do PROFLETRAS da UEMS e da UNEMAT, percebemos que a tendência privilegia, ainda, os materiais impressos - bidimensionais, planos e fixos. Mesmo que as interfaces digitais como os blogs e o facebook foram integrados no percurso de pesquisa, se justificaram ora para compartilhamento de materiais pelos próprios docentes, ora para publicação dos próprios textos produzidos pelos estudantes. Nenhuma das experiências compartilhadas demonstra o uso dessas interfaces digitais para incentivar e valorizar a escrita colaborativa em rede, a produção e interpretação de textos, bem como a interatividade com a hipertextualidade que agrega a convergência de mídias e de linguagens. 
Reafirmamos a necessidade de a escola e os docentes se atentaram para a emergência de instituir e valorizar as características e aspectos tipográficos visuais inerentes à pedagogia dos multiletramentos nas propostas e práticas de ensino de LP, considerando-se que a reflexão de que o letramento tradicional (da letra) é insuficiente às atuais demandas da vida cotidiana (MOITA LOPES e ROJO, 2004). Os tempos atuais demandam capacidades linguístico-discursivas próprias da cultura contemporânea, porque as práticas sociais do letramento são situadas histórico-socialmente.

É necessário, pois, que o PROFLETRAS, as escolas e os docentes de LP se atentem para as diretrizes que orientam os currículos de formação no que dizem respeito, sobretudo, a necessidade de examinar as potencialidades das interfaces e tecnologias digitais próprias da cibercultura, para refletir sobre as concepções de língua/linguagem em tempos contemporâneos em que os estudantes são considerados nativos digitais e grande parcela dos docentes é nativa da era analógica, como bem ilustram aquelas pesquisas em que as tecnologias digitais não foram incorporadas às práticas de multiletramentos. Isso implica dizer que o uso das tecnologias digitais, por si mesmas, não apaga as culturas locais e globais, nem tão pouco desvalorizam a diversidade linguístico-cultural de uma comunidade.

\section{AGRADECIMENTOS}

Agradecemos o apoio em forma de bolsas da CAPES para realização da pesquisa de Pós-doutoramento no Programa de Pósgraduação Stricto Sensu em Letras, Linha de Pesquisa Linguística Aplicada da UEMS, Unidade Universitária de Campo GrandeMS.

\section{REFERÊNCIAS}

BABINSKI, E. X. L. Hiperconto: a releitura de contos africanos como motivação para o letramento literário. 128 f. Programa de Pósgraduação Profissional em Letras da Universidade do Estado de Mato Grosso, Sinop/MT, 2015.

BAKHTIN, M. Estética da criação verbal. Tradução Paulo Bezerra. 6. ed. São Paulo: Martins Fontes, 2010.

BECKER, M. Processo de autoria: um percurso de oralidade e escrita. 104 f. Dissertação (Mestrado Profissional em Letras) Programa de Pós-graduação Profissional em Letras da Universidade do Estado de Mato Grosso, Sinop/MT, 2015.

BORTONI-RICARDO. S. M. O professor pesquisador: introdução à pesquisa qualitativa. São Paulo: Parábola Editorial, 2008.

BRITO, A. M. de S. Ensino de português na fronteira Brasil/Paraguay: valorização das línguas e das culturas. $74 \mathrm{f}$. Dissertação (Mestrado Profissional em Letras) - Programa de Pós-graduação em Letras da Universidade Estadual de Mato Grosso do Sul, Campo Grande/MS, 2015.

BUNZEN, C. Reflexões sobre práticas de letramento digital nos livros didáticos de português para o ensino fundamental II. In: BUNZEN, C. (org.). Livro didático de português: políticas, produção e ensino. São Carlos: Pedro \& João Editores, 2015. p. 107-128.

CANCLINI, N. G. Leitores, espectadores e internautas. Trad. Ana Goldberger. São Paulo: Iluminuras, 2008. Disponível em: http://everydayliteracies.net/files/NewLiteraciesSampler 2007.pdf. Acesso em: 18 set. 2016.

CASTELLS, M. A sociedade em rede. 6. ed. São Paulo: Paz e Terra, 1999.

CERVIERI, S. Práticas de letramento literário: uma proposta para o ensino fundamental. 69 f. Dissertação (Mestrado Profissional em Letras) - Programa de Pós-graduação Profissional em Letras da Universidade do Estado de Mato Grosso, Sinop/MT, 2015. 
CHARTIER, R. A aventura do livro: do leitor ao navegador. São Paulo: EDUNESP/Imprensa Oficial do Estado, 1997.

COSCARELLI, C. V.; KERSCH, D. F. Pedagogia dos multiletramentos: alunos conectados? novas escolas + novos professores. In: KERSCH, D. F.; COSCARELLI, C. V.; CANI, J. B. (org.). Multiletramentos e multimodalidade: ações pedagógicas aplicadas à linguagem. Campinas, SP: Pontes Editores, 2016. pp. 7-14.

COSTA, C. V. da. O facebook como espaço de circulação e socialização de textos de uma turma do $9^{\circ}$ ano do ensino fundamental. $83 \mathrm{f}$. Dissertação (Mestrado Profissional em Letras) - Programa de Pós-graduação em Letras da Universidade do Estado de Mato Grosso, Sinop/MT, 2015.

DIAS ANTÔNIO, M. S. Radioface e multiletramentos: ferramentas pedagógicas para o desenvolvimento da produção textual oral e escrita. 112 f. Dissertação (Mestrado Profissional em Letras) - Programa de Pós-graduação Profissional em Letras da Universidade do Estado de Mato Grosso, Sinop/MT, 2015.

FARIAS, D. A. F. A linguagem dos protestos: uma proposta pedagógica de SD por meio da análise discursiva dos cartazes das manifestações sociais. 95 f. Dissertação (Mestrado Profissional em Letras) - Programa de Pós-graduação em Letras da Universidade do Estado de Mato Grosso, Sinop/MT, 2015.

FREIRE, E. C. Letramento literário: a literatura africana e as novas tecnologias. 112 f. Programa de Pós-graduação Profissional em Letras da Universidade do Estado de Mato Grosso, Sinop/MT, 2015.

GIDDENS, A. Mundo em descontrole: o que a globalização está fazendo de nós. 2. ed. Rio de Janeiro: Record, 2002.

GONZALEZ ALÉM, A. O. F. O uso do blog nas aulas de língua portuguesa nas escolas municipais de Ponta Porã-MS. 77 f. Dissertação (Mestrado Profissional em Letras) - Programa de Pós-graduação em Letras da Universidade Estadual de Mato Grosso do Sul, Campo Grande/MS, 2015.

KALAZANTIS, M.; COPE, B. Changing the role of school. In: COPE, B.; KALAZANTIS, M. (org.). Multiliteracies: literacy learning and design of social futures. New York: Routledge, 2006 [2000]. p. 121-148.

KRESS, G. Literacy in the new media age. London: Routledge, 2003.

LEMOS, A. Cibercultura: tecnologia e vida social na cultura contemporânea. 5. ed. Porto Alegre: Sulina, 2010.

LEMOS, A. Infraestrutura para a cultura digital. In: SAVAZONI, R.; COHN, S. (org.). Cultura digital.br. Rio de Janeiro, RJ: Azougue Editorial, 2009. p. 315. Disponível em: https://www.procomum.org/wp-content/uploads/2018/01/cultura-digital-br.pdf. Acesso em: 13 out. 2017.

LÉVY, P. As tecnologias da inteligência: o futuro do pensamento na era da informática. São Paulo: Editora 34, 1993.

MACIEL, R. F; PARREIRA ONO, F. T. Desaprendendo para aprender: questionamentos sobre a formação docente. In: SANTOS, L. I. S.; MACIEL, R. F.; FORTILLI, S. de C. (org.). Formação docente e ensino de língua portuguesa: resultados e perspectivas do/no Profletras - região Centro-Oeste. Cáceres, MT: UNEMAT Editora, 2017. p. 344. 
MAISSIAT, J. et al. Interfaces digitais em objetos de aprendizagem: implicações na educação. In: Nuevas Ideas en Informática Educativa, TISE 2011, p. 144-149, 2011. Disponível em: http://www.tise.cl/volumen7/TISE2011/Documento19.pdf. Acesso em: 22 out. 2017 .

MALAGUTI, N. M. Letramento literário na EJA: estratégia para a leitura e a escrita. 112 f. Dissertação (Mestrado Profissional em Letras) - Programa de Pós-graduação Profissional em Letras da Universidade do Estado de Mato Grosso, Sinop/MT, 2015.

MAZOLINI, E. A. Práticas de multiletramentos: a revista escolar como suporte na(s) (trans)formação(ões) identitária(s) de estudantes do ensino fundamental. 147 f. Dissertação (Mestrado Profissional em Letras) Programa de Pós-graduação Profissional em Letras da Universidade do Estado de Mato Grosso, Sinop/MT, 2015.

MOITA LOPES, L. P.; ROJO, R. Linguagens, códigos e suas tecnologias. In: BRASIL/MEC/SEB/DPEM. Orientações curriculares de ensino médio. Brasília: MEC/SEB/DPEM, 2004, p. 14-56. Disponível em: http://portal.mec.gov.br/seb/arquivos/pdf/02Linguagens.pdf. Acesso em: 13 set. 2017.

OLIVEIRA, A. de. Textos multimodais em redes sociais: da leitura à produção de sentidos. 87 f. Dissertação (Mestrado Profissional em Letras) - Programa de Pós-graduação em Letras da Universidade do Estado de Mato Grosso, Sinop/MT, 2015.

OLIVEIRA, M. R. de. As HQs como ferramentas de incentivo à leitura e à produção textual. 110 f. Dissertação (Mestrado Profissional em Letras) - Programa de Pós-graduação Profissional em Letras da Universidade do Estado de Mato Grosso, Sinop/MT, 2015.

ROCHA, S. A. da. A magia da palavra nas histórias orais e escritas: uma proposta de fruição literária. 171 f. Dissertação (Mestrado Profissional em Letras) - Programa de Pós-graduação Profissional em Letras da Universidade do Estado de Mato Grosso, Sinop/MT, 2015.

ROJO, R. Letramentos múltiplos, escola e inclusão social. São Paulo: Parábola Editorial, 2009.

ROJO, R.; MOURA, E. (org.). Multiletramentos na escola. São Paulo: Parábola Editorial, 2012.

ROJO, R. Pedagogia dos multiletramentos: diversidade cultural e de linguagens na escola. In: ROJO, R.; MOURA, E. (org.). Multiletramentos na escola. São Paulo SP: Parábola Editora. 2012. p. 11-31.

ROJO, R. (org.). Escola conectada: os multiletramentos e as TICs. São Paulo: Parábola Editorial, 2013.

SABOIA, E. D. Propagandas e campanhas publicitárias em cartazes: uma proposta de leitura e produção textual. 267 f. Dissertação (Mestrado Profissional em Letras) - Programa de Pós-graduação Profissional em Letras da Universidade do Estado de Mato Grosso, Sinop/MT, 2015.

SANTAELLA, L. Linguagens líquidas na era da mobilidade. São Paulo: Paulus, 2007.

SANTAELLA, L. Navegar no ciberespaço: o perfil cognitivo do leitor imersivo. São Paulo: Paulus, 2008.

SANTOS, Â. M. dos. O uso do hipertexto no estudo dos gêneros textuais orais e escritos. 104 f. Dissertação (Mestrado Profissional em Letras) - Programa de Pós-graduação em Letras da Universidade Estadual de Mato Grosso do Sul, Campo Grande/MS, 2015. 
SANTOS, L. I. S. Unidades mato-grossenses do PROFLETRAS: abrangência, resultados e perspectivas. Letras \& Letras, Uberlândia, v. 32/2, p.16-45, jul./dez. 2016.

SANTOS, L. I. S.; SANTOS, L. A. O. dos. Crenças e expectativas tecidas pelos docentes-alunos de língua portuguesa do mestrado profletras. Signótica, Goiânia, v. 28, n. 2, p. 257-284, jul./dez. 2016.

SCRIMIM, P. S. da S. Rede social na escola: o facebook como ferramenta de incentivo à leitura e à produção textual. $83 \mathrm{f}$. Dissertação (Mestrado Profissional em Letras) - Programa de Pós-graduação Profissional em Letras da Universidade do Estado de Mato Grosso, Sinop/MT, 2015.

SILVA, M. Sala de aula interativa: educação, comunicação, mídia clássica... 5. ed. São Paulo: Edições Loyola, 2010.

SILVA, A. J. da. O letramento literário: transcrição da poesia produzida em Mato Grosso em infopoema. 80 f. Dissertação (Mestrado Profissional em Letras) - Programa de Pós-graduação em Letras da Universidade do Estado de Mato Grosso, Sinop/MT, 2015.

SILVA, C. F. da. Processo de autoria: o uso da ferramenta digital pixton na produção do gênero história em quadrinhos. $67 \mathrm{f}$. Dissertação (Mestrado Profissional em Letras) - Programa de Pós-graduação em Letras da Universidade do Estado de Mato Grosso, Sinop/MT, 2015.

SILVA, A. P. de P. Formação continuada de professores para o projeto UCA: análise dos processos formativos prescritos, vivenciados e narrados. 330 f. Tese (Doutorado em Educação) - Programa de Pós-Graduação em Educação da Universidade Federal do Rio Grande do Sul, Porto Alegre, 2014.

SILVA, A. P. de P.; SANTOS, L. I. S. Formação continuada de docentes de língua portuguesa de escolas públicas brasileiras: o Profletras e a perspectiva dos multiletramentos, 2018 , no prelo.

SOUZA, M. S. A. A. B. Alunos leitores: uma experiência prazerosa. 62 f. Dissertação (Mestrado Profissional em Letras) - Programa de Pós-graduação em Letras da Universidade Estadual de Mato Grosso do Sul, Campo Grande/MS, 2015.

SOUZA, M. M. S. de. Multiletramentos e o uso do rádio na escola: a leitura e a escrita nesse processo. 147 f. Dissertação (Mestrado Profissional em Letras) - Programa de Pós-graduação Profissional em Letras da Universidade do Estado de Mato Grosso, Sinop/MT, 2015.

TEIXEIRA, F. E. V. Gêneros Textuais escritos e orais - celular uma mídia possível? 85 f. Dissertação (Mestrado Profissional em Letras) - Programa de Pós-graduação da Universidade Estadual de Mato Grosso do Sul, Campo Grande/MS, 2015.

TORALES, F. A. O texto literário na escola como instrumento de incentivo à leitura e de avanço linguístico e cultural. 120 f. Dissertação (Mestrado Profissional em Letras) - Programa de Pós-graduação em Letras da Universidade Estadual de Mato Grosso do Sul, Campo Grande/MS, 2016. 
VIANA, L.Z.F. da S. A produção de jornal no $6^{\circ}$ ano do ensino fundamental. 152f. Dissertação (Mestrado Profissional em Letras) Programa de Pós-graduação em Letras da Universidade Estadual de Mato Grosso do Sul, Campo Grande/MS, 2015.

WEBER, M. O multiletramento e as tecnologias digitais: constituição de uma identidade autora. 136 f. Dissertação (Mestrado Profissional em Letras) - Programa de Pós-graduação Profissional em Letras da Universidade do Estado de Mato Grosso, Sinop/MT, 2015.

\section{(c) (1) $(\circledast$}

Recebido em 30/01/2019. Aceito em 06/06/2019. 